\title{
Coleçoees editoriais de baixo custo e traduçōes de romances franceses no acervo do Grêmio Literário Português do Pará
}

Cheap serialized editions and translations of french novels in the collection of Grêmio Literário Português do Pará

Valéria Augusti

Universidade Federal do Pará, Belém, PA, Brasil

\begin{abstract}
Resumo: O Brasil do século XIX foi mercado consumidor de coleções editoriais de origem europeia, caracterizadas pelo baixo custo de seus exemplares. Esse tipo de empreendimento editorial, que visava a baratear o livro, tornando-o acessível ao leitor menos abastado financeiramente, também foi importante para a constituição dos acervos de gabinetes de leitura brasileiros, como o do Grêmio Literário Português do Pará, fundado em 1867. No acervo desse gabinete há quantidade significativa de romances franceses, traduzidos ou não, que fazem parte dessas coleções. Este artigo pretende discorrer sobre essas coleções, bem como sobre dois tradutores de romances franceses cuja presença no acervo é significativa. Palavras-chave: Gabinetes de leitura. Coleções editoriais de baixo custo. Tradução de romances franceses. Século XIX.
\end{abstract}

Abstract: In the nineteenth century, Brazil was a consumer of European serialized editions that were characterized for being inexpensive. This type of publishing entrepreneurship, aimed at reducing the prices of books and making them financially accessible for lowerclass readers, was important for the emergence of collections in Brazilian reading cabinets, such as the Gremio Literário Português, founded in 1867. In its collection there is a great amount of original and translated French novels. This article analyzes these serialized editions, as well as two translators of French novels who were responsible for a relevant part of the collection studied.

Keywords: Reading cabinets. Cheap serialized editions. Translation of French novels. Nineteenth century. 


\section{Produção e circulação de edições de baixo custo na França do século XIX}

Conforme bem o assinala Márcia Abreu (2011), a globalização da cultura, longe de ser um fenômeno recente, remonta pelo menos aos primórdios do século XVI, capitaneada pelas monarquias ibéricas que, por meio de seus navios, conectaram as quatro partes do mundo, fazendo circular inúmeros produtos e, entre eles, livros.

Se as elites da Europa Ocidental assustaram-se, no século XVIII, com a "fome de leitura" por parte de um público que não se identificava Valéria com essa "fome" do ponto de vista da pertença socioeconômica e que Augusti tampouco chegava a assumir proporções significativas do ponto de vista quantitativo (WITTMANN, 1999), que dizer do século XIX, momento em que a concepção do ensino universal como atributo do Estado ganhou espaço nas principais nações europeias, reduzindo as taxas de analfabetismo a números nunca antes vistos? (LYONS, 1999). A expansão do ensino formal obrigatório e a redução da jornada de trabalho, se comparada ao período da Revolução Industrial, criaram novos públicos, como as mulheres, as crianças e os operários, que se interessavam por periódicos os mais diversos, por manuais de cozinha, contos de fadas, romances etc. (LYONS, 1999).

O mercado editorial, atento ao surgimento desses novos públicos, respondeu-lhe à altura, apostando na publicação de obras em língua vulgar em detrimento do latim, cujos estertores já haviam se confirmado nas feiras de livros do século XVIII, como as de Leipzig (WITTMANN, 1999). As inovações tecnológicas no campo da imprensa, a mecanização da produção de papel e de outras áreas, como a dos transportes, possibilitaram que o aumento da capacidade produtiva em termos de volumes de livros se somasse às facilidades de eles circularem não apenas na Europa Ocidental, mas também além-mar (ABREU, 2011; ANDRADE, 2004). Se o comércio do livro em termos de volume de produção atingiu grandes proporções na Inglaterra e na Alemanha, empregando contingentes enormes de profissionais, a primeira delas exportando seus produtos para as colônias e a segunda escoando sua produção sobretudo para a Europa Eslava, Romênia e Escandinávia, foi a França, cuja produção editorial custou mais a se igualar a dessas duas potências, que ocupou

uma centralidade cultural ímpar no período, expressa tanto pela francofonia, da qual participavam as elites sócio-políticas e cultu- 
rais de outras nações europeias, quanto pelo extraordinário pres-

tígio da literatura francesa em escala mundial, que permaneceu inconteste até meados do século XX. (ABREU, 2011, p. 118).

Nos primórdios do século XX, o aumento de títulos e do número de exemplares, acompanhados de edições baratas, voltadas para públicos amplos, colocou a França à frente da Alemanha e da Inglaterra, com tiragens superiores a 100 mil exemplares, que, certamente, como assinala Abreu, teriam por destino países estrangeiros. Esse movimento - que incluía não apenas livros franceses, mas também ingleses e alemães traduzidos para o francês - já vinha, no entanto, se manifestando no século anterior, uma vez que em 1890 a França exportava 4.700 toneladas de livros (ABREU, 2011).

Coleções

editoriais de baixo custo $e$ traduções de romances franceses no acervo do Grêmio Literário Português do Pará

Jean-Yves Mollier afirma, a respeito da edição francesa no período compreendido entre 1750 e 1838, que é perceptível o desejo, por parte dos editores, "em realizar pequenas obras a bom preço, com impressão medíocre e cujo material permitisse [a], a priori, esperar atingir camadas ou categorias sociais que antes não haviam considerado o livro como um elemento passível de mobiliar o espaço doméstico" (MOLLIER, 2008, p. 24). Editores como Pierre-Jules Hetzel e Michel Lévy empenharam-se, assim, na criação de coleções, intituladas "Diamants", "Des voyageurs" ou, ainda, "Chemins de Fer", publicadas em pequenos formatos e vendidas a preços módicos. Além disso, a partir de 1840, Michel Lévy, assim como outros livreiros interessados em um público menos favorecido em termos econômicos, começou a comercializar volumes fracionados em fascículos, substituindo o sistema de subscrição que marcara o Antigo Regime. 0 preço dos fascículos ilustrados vendidos, a princípio, por 50 centavos, chegou a baixar para 30 centavos em 1845. No repertório de obras publicadas, autores como Pixérécourt, Pigault-Lebrun e Charles Desnoyers. Na origem do empreendimento que barateava o preço do volume, dividindo-o em fascículos, estava, segundo Mollier, a intenção de concorrer com o romance-folhetim publicado nos rodapés dos jornais. 0 romance folhetim havia modificado as condições do mercado francês, fazendo surgir o folhetinista ligado a um jornal e o acesso à prosa de ficção vendida em um suporte material de baixíssimo custo, o periódico. Assim, o objetivo da coleção Charpentier, por exemplo, era acabar com o reinado dos folhetins costurados à mão, oferecendo ao público leitor obras vendidas a 2 francos o volume (MOLLIER, 2008). 
A edição de romances em fascículos vendidos a preços módicos, que se proliferou nos anos 1840-1845, em empreendimentos levados a cabo por Gustave Havard, Michel Lévy e Gustave Barba procurava, assim, atingir um público nascido em um meio popular e cativo dos folhetins, mas não somente. ${ }^{1}$ Pretendia, também, fazer concorrência aos gabinetes de leitura ${ }^{2}$, permitindo que os leitores de baixa renda constituíssem sua biblioteca pessoal em vez de alugar obras a 20 centavos o volume. Contudo, o barateamento das edições tinha seus inconvenientes, como a preferência por autores que haviam caído em domínio Valéria público em detrimento das últimas novidades literárias. Se deixar de pagar os direitos de autor auxiliava na redução dos custos de impressão, por outro lado se mostrava pouco atrativo para aqueles que desejavam ler os autores em voga. A despeito disso, a coleção Charpentier, de Michel Lévy, publicada no formato in- $18^{\circ}(18,5 \times 11,5)$ e ancorada em contratos com escritores populares, garantiu tiragens médias de 6.600 exemplares, com reimpressões chegando a 3.300 exemplares (MOLLIER, 2008).

Paradoxalmente, o escoamento dessa produção, que atinge cifras impressionantes nos idos de 1867, muito embora amargue uma queda de distribuição por parte dos vendedores ambulantes, acaba tendo sua existência garantida pelas “2.428 livrarias de província em 1851, 3.724 em 1861, 4.062 em 1863 e 5.086 em 1877 (LYONS, 1987); 43 bibliotecas de estações em 1853, 162 em 1861, perto de $500 \mathrm{dez}$ anos mais tarde" (MOLLIER, 2008 , p. 51). Em suma, livrarias e bibliotecas parecem ter sido um mercado garantido para o escoamento dessa produção em que o romance, até os primórdios do século XX, ocupava posição central (MOLLIER, 2008).

\section{Produção e circulação de edições de baixo custo em Portugal}

A tendência no sentido de baratear as edições atingiu também a Península Ibérica. No caso de Portugal, em particular, já havia uma relação forte estabelecida com a França, desde o século XVIII, quando habitantes de Briançon, comuna situada nos Altos Alpes franceses, emigraram para Portugal provavelmente em virtude da piora da situação econômica do Delfinado (GUEDES, 1998). Entre aqueles que se dedicaram ao

1 Mollier afirma que, comparando o preço de venda das peças de teatro ao dos romances na primeira metade do século XIX francês, sem dúvida alguma, o espectador de teatro comprava mais facilmente os volumes do primeiro do que os do segundo, "expostos nas vitrines das lojas da capital" (MOLLIER, 2008, p. 30).

2 Ele está se referindo às boutiques à lire, ou seja, àqueles gabinetes que alugavam obras, e não aos de caráter associativo, que se sustentavam pelo sistema de subscrição. 
mercado editorial estavam os irmãos Borel, Martin, Bertrand, Aillaud, Pierre e Georges Rey, Orcel, irmãos Dubeux e Sémion, Bonnardel, Colomb, Ginioux, Guilbert, Mallen, Reycend e Rolland (GUEDES, 1998). Esses livreiros estrangeiros instalados em Portugal, ainda que nem sempre tivessem chegado com capital suficiente para abrir uma empresa, o que os obrigou a trabalhar a princípio como colpourteurs, passaram a abastecer bibliotecas reais e conventuais e a satisfazer a curiosidade dos leitores com uma variedade significativa de obras, incluindo aquelas proibidas pela censura portuguesa (EL FAR, 2004; GUEDES, 1998).

Para além disso, estabeleceram uma via de comércio exterior com outras nações da Europa. Em meados do século XVIII, os livros de contas dos Cramer, impressores e livreiros instalados em Genebra, evidenciam o negócio lucrativo que mantinham com briançoneses instalados em Portugal, como os irmãos Bertrand, Joseph Bonnardel, irmãos Ginioux, Joseph Colomb, Borel, entre outros (GUEDES, 1998). Como também observa El Far (2004), as relações desses livreiros com as tipografias situadas em Genebra, Lausanne e Neuchâtel eram intensas, uma vez que nas primeiras décadas do século XVIII a produção portuguesa de livros era escassa, de forma que boa parte dos títulos vinha de países onde as técnicas de edição estavam mais adiantadas. Dessa maneira, podemos considerar que o papel dos editores briançoneses que se instalaram em Portugal foi de suma importância, pois eles ligaram Portugal ao mercado internacional de livros e, com o fim do controle do Estado sobre as publicações, inseriram a edição portuguesa no compasso das demais nações europeias, que perseguiam os leitores barateando o custo das edições (EL FAR, 2004).

No que tange à circulação das publicações feitas em Portugal, resta assinalar que boa parte dela, no século XIX, ancorava nos portos brasileiros, como o do Rio de Janeiro (EL FAR, 2004) e o de outras províncias. Portugal, ao contrário do que ocorrera na França, Inglaterra e Alemanha, não garantira a universalização do ensino a sua população, de forma que, em 1890, 79,2\% dela não sabia ler nem escrever, o que fazia do Brasil um mercado atraente para os editores portugueses. Somente nas grandes cidades, como Lisboa e Porto, essas cifras caíam para $47,56 \%$ e 54,05\%, respectivamente (EL FAR, 2004). Na cidade de Lisboa se concentrava, segundo afirma El Far, uma produção editorial significativa se comparada àquela do Porto e de Coimbra. Desde as décadas de 1820 e 1840, os editores portugueses, inclusive apoiados pelo governo português, vinham tentando alcançar um público leitor mais amplo e 
obter uma maior faixa de lucro, publicando volumes a custos mais baixos. Daí o surgimento de séries econômicas de autores clássicos portugueses, bem como de autores estrangeiros traduzidos.

Em 1842, José Feliciano de Castilho e José Pereira Marrecos, administrador da Imprensa Nacional, foram incumbidos, por despacho ministerial, de participar de uma comissão que deveria reimprimir, à custa do Estado, os clássicos portugueses. Ainda que o projeto não tenha sido levado a cabo, três anos depois José Feliciano de Castilho e seu irmão, Antonio Feliciano de Castilho, deram início à "Livraria Clássica Portuguesa", Valéria coleção em que se pretendia dar a ler os principais escritores portugueses Augusti (SANTOS, 1985). No que tange ao público-alvo, seus idealizadores manifestavam a intenção de retirar as obras do circuito dos "doutos", oferecendo aos leitores títulos publicados em múltiplos formatos, a preços por eles considerados acessíveis. Foi com essa intenção que publicaram uma edição barata das obras de Camões, ressaltando o desejo de difundir entre as "classes pobres" o desejo pela leitura (SANTOS, 1985). Contudo, foi na segunda metade do século que tiveram início os empreendimentos voltados para a publicação barata de autores contemporâneos, como foi o caso de três séries de coleções empreendidas pelo segundo Antonio Maria Pereira (19--), duas delas publicadas com seu nome e uma terceira com o título "Coleção Econômica". No entanto, ao contrário das iniciativas anteriormente citadas, esta se caracterizava por publicar autores nacionais e estrangeiros e, no que diz respeito aos gêneros literários, por se dedicar a uma variedade deles: contos, lendas, crônicas e peças de teatro que já haviam feito sucesso nos palcos (SANTOS, 1985).

Entretanto, interessa assinalar a atenção que o romance estrangeiro recebeu por parte desses editores portugueses. Alessandra El Far (2004) elenca os inúmeros autores franceses que ganharam traduções para o português: Paul de Kock, Xavier de Montepin, Honoré de Balzac, Julio Verne, entre outros. Ainda que gerasse inúmeras reclamações por parte dos escritores portugueses, cujas obras concorriam com a prosa de ficção estrangeira, "o romance francês traduzido, impresso em pequenas brochuras e vendido a preços módicos, animou o comércio livreiro por ter sido visto como um empreendimento seguro e rentável" (EL FAR, 2004, p. 54). Assim como ocorrera na França, os editores portugueses colocaram à venda, na segunda metade do século, o texto vendido em fascículos. Desse modo, quem não podia pagar por um volume na íntegra tinha a possibilidade de adquiri-lo aos pedaços. Concomitan- 
temente a essa fórmula editorial, deu-se preferência para impressões pouco cuidadas, em papel de má qualidade e com capas em brochura em detrimento das edições luxuosas, que não desapareceram, mas reduziram sua expressividade em termos quantitativos (EL FAR, 2004).

Maria de Lourdes Lima dos Santos (1985) afirma que as obras lançadas no circuito dito "popular" eram, sobretudo, traduções de autores franceses como Sue, Dumas, Balzac, Scribe e Paul de Kock, o qual, nos primórdios dos anos 1850, teve suas obras publicadas em cadernetas de 64 páginas, impressas em papel de péssima qualidade e vendidas a 40 réis.

A despeito do baixo preço, as obras nem sempre eram adquiridas pelos leitores, mas sim emprestadas dos gabinetes de leitura que "constituíam um apoio importante para os livros lançados no circuito popular", pois dispunham de catálogos com as obras em estoque. Além Coleções editoriais de baixo custo $e$ traduções de romances franceses no acervo do Grêmio Literário Português do Pará disso, alguns gabinetes mantinham ligações diretas com empresas editoriais ou livreiras, caso do gabinete dirigido por Mademoiselle Férin e por Pedro Bornnadel, ambos ligados ao negócio livreiro (SANTOS, 1985, p. 190). Muito embora desdenhados pelas elites letradas portuguesas e ridicularizados por escritores como Almeida Garret e Teixeira de Vasconcelos, eram autores como Arlincourt e Paul de Kock que, segundo Santos (1985), faziam sucesso incomensurável junto ao público leitor.

No que tange ao circuito que, envolvendo uma série de profissionais ligados ao mundo do livro, garantia que este último chegasse às mãos dos leitores, importa notar o papel significativo daqueles que asseguravam a leitura de autores estrangeiros na língua de destino: os tradutores. Alguns autores franceses, em virtude de sua grande aceitação, eram traduzidos e, posteriormente, “imitados" pelos próprios tradutores que não queriam abrir mão da rentabilidade proporcionada por eles. Santos (1985) faz referência a pelo menos quatro casos dessa natureza, o de A. J. Nery, tradutor de Paul de Kock, o de José da Fonseca, tradutor de Lesage, que o imitou em títulos como História de D. Afonso Braz, filho de Gil Blaz de Santilhana e Aventuras de Gil Blaz compendiadas para uso dos meninos, e, por fim, o de Sotto Mayor e de Alfredo Possolo Hogan, que

\footnotetext{
se aproveitaram do sucesso de Sue e Dumas, adaptando-os ou imitando-os respectivamente com Frei Paulo ou os Mysterios de Lisboa (1844), um sucesso editorial raro em autores nacionais; e com A mão do finado (1853), continuação apócrifa de $O$ conde de Monte Cristo. (SANTOS, 1985, p. 192).
} 
Chama a atenção particularmente o caso daqueles que, na condição inicial de tradutores ou mesmo de profissionais de outras áreas, decidiram se tornar editores de coleções baratas, como foi o caso de João Luís Rodrigues Trigueiros, que era tradutor nas horas vagas e se tornou editor da coleção "Biblioteca Romântica Luso-Brasileira", e de Eduardo de Faria, amanuense que pediu exoneração para se dedicar à função de editor da "Biblioteca Romântica". Ambas as coleções chegaram a publicar cerca de cinquenta romances, todos eles de autores como Sue, Kock, Féval, Ponson etc. (SANTOS, 1985).

Valéria Outra iniciativa semelhante foi levada a cabo por David CoAugusti razzi, que, iniciando sua atividade de editor com um romance de Ponson Du Terrail, acabou por criar a empresa Horas Românticas, especialmente dedicada a autores de prestígio no exterior, cujas obras eram vertidas para o português por um grupo de tradutores e vendidas em fascículos. Os livros de Corazzi não tinham como destino apenas o mercado interno português; pelo contrário, assim como ocorrera em nações como a Inglaterra e Alemanha, o editor estabeleceu comércio com várias partes do mundo, como a África, a China, a Europa e a América, pautando-se numa rede de correspondentes que distribuía as obras por encomenda (EL FAR, 2004). No Brasil, contava com uma filial no Rio de Janeiro, que se encarregava de remeter aos interessados os catálogos e prospectos e fazer assinaturas das publicações do editor português.

É importante observar, no entanto, que entre as obras importadas no período anterior a 1834 já havia traduções portuguesas publicadas na França. Segundo Santos (1989), portugueses exilados trabalhavam para editoras francesas realizando traduções, como foi o caso de Barreto Feio, de Antonio da Costa Paiva e do bacharel brasileiro Caetano Lopes de Moura. Além desses nomes mais conhecidos, uma miríade de tradutores anônimos se dedicou a escrever "versões" de originais franceses. Analisando o recenseamento feito por Vitor Ramos em A edição da língua portuguesa em França (1800-1850), Santos (1985) observa que foram localizados pelo menos quinhentos títulos impressos na França em língua portuguesa, havendo, entre eles, aproximadamente 190 traduções, que avultaram após a instalação do Governo Liberal (1836-1838). 


\section{Presença de coleções de baixo custo no Grêmio Literário Português do Pará}

Parcela significativa dos exemplares de prosa de ficção de origem francesa - traduzida ou não para o português - abasteceu não somente os periódicos, o mercado livreiro e as bibliotecas e gabinetes de leitura da capital do Império brasileiro, como também as estantes do Grêmio Literário Português do Pará, gabinete de leitura fundado em 1867 pela colônia portuguesa residente na capital dessa província (BRITO, 1994; AUGUSTI, 2011).

Muito embora atualmente consigamos obter apenas um instantâneo desse acervo que sobreviveu a incêndios, assim como à perda de obras decorrentes de empréstimos ou mesmo de processos de degradação, é evidente a presença, em suas estantes, das mais diversas coleções empreendidas por livreiros-editores instalados seja em solo português, seja em solo francês. Assim, é possível encontrar exemplares pertencentes à "A Nova Colecção Popular", da Antiga Casa Bertrand José Bastos; à "Biblioteca para Senhoras", empreendimento da Livraria Internacional de Ernesto e Eugênio Chardron; ou, ainda, à "Biblioteca Alexandre Dumas", levada a cabo pelo "Escriptorio da Empresa"; à "Biblioteca de Algibeira", do francês Garnier, instalado no Rio de Janeiro; à "Biblioteca do Jornal das Senhoras", coleção impressa na tipografia do periódico de mesmo nome; ou à "Bibliotheca dos Dous Mundos", título que parece ter animado tanto ao Escriptorio da Empresa quanto à Sociedade Tipográfica Franco-Portuguesa. As coleções que sugerem a natureza "econômica" do empreendimento são várias: "Biblioteca Econômica", título do projeto editorial da Tipografia Universal de Faria \& Cia, situada na Rua dos Calafates $n^{\circ}$ 113, e da Companhia Editora de Publicações Illustradas; situada na Travessa da Queimada nº 35, ambas em Lisboa. Também a coleção "Bibliotheca Popular", impressa pela Tipografia de Salles, situada no Largo de São Domingos, e a "Bibliotheca Popular", da Empresa Editora de Publicações Illustradas, situada na Rua do Rosa no 162, em Lisboa, parecem ter intentado atingir um público leitor amplo e menos provido em termos econômicos. Foi no interior da "Bibliotheca Popular Romântica", situada no Porto e com obras impressas pela Tipografia Alliança, que vieram à luz exemplares das obras de Paul Féval e, no interior da "Grande Edição Popular", de David Corazzi, que foram publicados exemplares do romancista Jules Verne. "Jardim do Povo ou Biblioteca Econômica” foi o título dado pela Tipografia Portuguesa a um conjunto de exemplares de obras de Paul Féval, Paul Duplessis, Alexandre Dumas, entre outros. Ao 
que tudo indica, uma "empresa" foi especialmente constituída para publicar a coleção "Bibliotheca Serões Românticos", impressa na tipografia de mesmo nome, situada na Rua da Cruz de Pau, em Lisboa; nela foram publicadas obras de Du Boisgobey, Xavier de Montèpin, Emile Gaboriau, Paul Féval etc. $O$ título "Bibliotheca Universal” também agradou a diversos agentes do mercado livreiro, como o já referido Escriptorio da Empresa, a Typografia Lisbonense, de Aguiar Vianna, e a Casa Editora David Corazzi, que acrescentou ao título os adjetivos "Antiga e Moderna”. A “Coleção Lusitânia”, da livraria Chardron de Lello \& Irmão Editores, não Valéria se restringiu, a despeito no nome, à publicação de obras portuguesas, pelo Augusti contrário. De seus prelos saíram obras de Jacques Cazzote, Chateaubriand, Honoré de Balzac, Dumas Filho, Gustave Flaubert, Alphonse Daudet, Victor Hugo, Lamartine, entre outros. A coleção "Pedro Corrêa", nome do próprio editor, que se instalou na Rua do Carvalho, em Lisboa, publicou autores os mais diversos, como Joseph Méry, Jules Sandeau, Emile Gaboriau, Charles Deslys, entre outros.

Todas essas coleções, cujos títulos ora sugerem o preço acessível de seus volumes - "Popular" -, ora a natureza das obras - "antigas e modernas" -, ou até mesmo o destino geográfico que se imaginava para seus volumes - "os dous mundos" -, se dedicaram à publicação de exemplares de prosa de ficção francesa que aportaram na Província do Pará no século XIX, graças a um circuito amplo de difusão do livro, envolvendo não apenas autores, como também editores, gráficos, fornecedores, distribuidores, livreiros etc. (DARNTON, 1990). No entanto, para muitos dos leitores do gabinete de leitura instalado na Província do Pará, o contato com a prosa de ficção francesa publicada ou não no interior dessas coleções dependeu de um personagem que parece ter sido negligenciado por Robert Darnton ao propor um modelo de circuito de difusão do livro: o tradutor. Podemos afirmar que aproximadamente $70 \%$ dos exemplares de prosa de ficção francesa publicada no século XIX e disponível no acervo da instituição são traduções para a língua portuguesa. ${ }^{3}$ Ainda que se trate de uma parcela significativa do acervo em termos quantitativos, não resta dúvida de que poucos são os responsáveis por essas traduções cujos nomes soam familiares ao leitor do século XXI. Geralmente isso se dá quando o tradutor em questão atuou em outros campos do mundo do livro, como é o caso de Pinheiro Chagas, que alcançou respeitabilidade ainda no século XIX

3 Essa porcentagem é aproximada, uma vez que o processo de catalogação dos exemplares não terminou. 
em virtude de suas atividades como crítico literário. 0 acervo de prosa de ficção francesa do Grêmio Literário Português do Pará sugere que o prestigiado crítico português também teve uma atuação significativa como tradutor, vertendo para a língua portuguesa obras de Julio Verne, Frèderic Soulié, Alexandre Dumas Fils, Paul Féval, Lamartine, Camille Debans, G. de La Landelle, entre outros.

No entanto, que dizer de tradutores como João Luis Rodrigues Trigueiros, responsável por verter para a língua portuguesa um sem número de obras de autores como Eugène Sue, Xavier de Montépin, Ponson du Terrail e Alexandre Dumas? Uma breve investigação biográfica sobre João Luis Rodrigues Trigueiros leva a crer que tenha nascido na Pedreira, freguesia de São Tiago da Vila de Almada, em 1824, e falecido em Lisboa após $1883 .{ }^{4} \mathrm{O}$ tradutor teria cursado o Liceu e a Aula de Comércio, entrando posteriormente para o Ministério da Guerra, em que ocupara vários cargos, entre eles o de chefe da $1^{\mathfrak{a}}$ Repartição da Administração Militar. Sobre ele, um de seus descendentes afirma:

A ele se deve, em Portugal, o conhecimento da maioria dos romancistas franceses de meados do século XIX, dos quais foi tradutor. [...] Organizou a Biblioteca Romântica Luso-brasilei$\mathrm{ra}^{5}$, fazendo inúmeras traduções, quase sempre por sua conta. Foi condecorado com a Ordem de Nossa Senhora da Conceição. (TRIGUEIROS, 2013).

Ainda assim, não encontramos qualquer referência ao nome do tradutor no Diccionário Bibliográfico Português (1810-1876), de Innocêncio Francisco da Silva (1859). Contudo, no acervo do Grêmio Literário Português constam, atualmente, 49 volumes traduzidos por Trigueiros, compreendendo o período entre 1854 e 1878, o que significa pelo menos 24 anos de atuação como tradutor.

Essa dificuldade de encontrar informações não se dá no caso de Francisco Ferreira da Silva Vieira, tradutor de pelo menos 28 volumes de romances franceses do acervo do Grêmio Literário Português do Pará. Em verbete do Dicionário Histórico de Portugal, sabemos que nasceu em 1851 e faleceu em

4 As informações sobre a família Trigueiros podem ser obtidas no site <http://familiatrigueiros. blogspot.com.br/>. Acesso em: 30 abr. 2013.

5 Conforme consta no site do projeto "Memória de Leitura", a Biblioteca Romântica Luso-Brasileira teria sido fundada em 1846, por iniciativa de João Luís Rodrigues Trigueiros (MEMÓRIA DE LEITURA, 2013). 
1888. Identificado como "tipógrafo e escritor", teria vindo ao Brasil forçadamente, em virtude da precária situação econômica dos pais, acabando por aportar no Maranhão, onde trabalhou como caixeiro. No Brasil é que teria apreendido a arte tipográfica, antes de retornar definitivamente a Portugal para trabalhar em "diversas imprensas de Lisboa". Segundo informa o dicionário, teria sido diretor tipográfico da imprensa de Gonçalves Lopes, atuando nela como diretor e revisor do periódico $O$ Povo, de propriedade de seu irmão mais velho, José Martiniano da Silva Vieira. Findo o periódico em questão no ano de 1856, teria dado início à atividade de tradutor, inicialValéria mente para a editora de Gonçalves Lopes. Vestígio de sua atividade junto à Augusti editora encontra-se no acervo do Grêmio, com a obra Mysterio dos conventos, publicada em 1863 em Lisboa, por F. Gonçalves Lopes, editor. Muito embora não conste o endereço do editor na obra, sabe-se que fora impressa na Tipografia do Futuro. Antes, porém, de traduzir esse romance, Francisco Ferreira da Silva Vieira já traduzira o romance de Alexandre Dumas Filho, Processo de Clemanceau: memória escripta pelo réo, publicado em 1833 pela Typographia do Futuro, situada na Rua da Cruz de Pau no 35. Na folha de rosto da obra, as iniciais ornamentadas "GL" fazem crer que se trata de uma edição de Gonçalves Lopes ${ }^{6}$, que, provavelmente, era proprietário da Typografia do Futuro ou pelo menos a utilizava para imprimir essas obras. Pela mesma tipografia foram publicadas suas traduções de 0 homem que ri e Os miseráveis, ambos de Victor Hugo. A tradução da primeira obra veio à luz em 1869, e a segunda em cinco volumes publicados entre os anos de 1875 e 1877. No entanto, o endereço da tipografia não era mais o mesmo, situando-se na Rua de $\mathrm{S}$. Boaventura $\mathrm{n}^{\circ} \mathbf{5 7}$. Some-se a isso o fato de o próprio nome da tipografia mudar nas edições de 1876 e 1877, quando passou a se chamar Imprensa Democrática. Contudo, em todos os volumes permanecem as iniciais "GL", as quais, cremos, identificam o editor Gonçalves Lopes. Na década de 1870, Francisco Ferreira fez traduções para duas coleções, lançadas por diferentes empresas. De Xavier de Montépin traduziu Os dois Zuavos, romance publicado em dois tomos, ambos no ano de 1876 pela Bibliotheca dos Bons Livros,

\footnotetext{
6 Na edição do $1^{\circ}$ volume de Os operários do mar, de Victor Hugo, impresso na Typographia do Futuro, consta, nas páginas finais, uma espécie de aviso ao leitor, identificado em letras garrafais com o título "Empresa Editora - Gonçalves Lopes". Com essa obra, afirma o editor, encerravam-se os sessenta volumes já publicados regularmente por ele. A respeito do empreendimento, afirma: "todas as edições, traduzidas ou originaes, estão completas. Temos certeza de que a escolha tem sido boa, e a tradução fiel, porque as cartas com que alguns dos nossos assignantes nos tem honrado, são disto a prova mais convincente que podíamos receber: assim como a perseverança com que tem auxiliado os nossos esforços." (HUGO, 1866, n.p.).
} 
empreendimento do Escriptorio da Empresa, situado na Rua de Santo Antão $n^{\circ} 100,1^{\circ}$ andar. A tipografia responsável pela impressão foi a Typ. Lisbonense, no Largo de S. Roque $\mathrm{n}^{\mathrm{o}}$ 7. Supomos, portanto, que o Escriptorio da Empresa cumprisse, pois, o papel de editora, já que fazia imprimir as obras em tipografia de outrem. Para o editor J. A. Xavier de Magalhães, responsável pela Bibliotheca Popular, traduziu, em três volumes, 0 médico dos ladrões ou Pariz em 1870, de Henry de Kock, filho do romancista Paul de Kock. Para a “Colecção de romances dos melhores autores", empreendimento da Typographia Lisbonense, traduziu As últimas proezas do Rocambole, de Ponson du Terrail, nos anos de 1870 e 1871, em três volumes. Também traduziu Escolhidos e réprobos, de Émile Souvestre, em 1861, para a "editora" de J. P. Martins Lavado, situada na Rua Augusta no 31 .

A despeito da importância que tiveram como intermediários entre Coleções editoriais de baixo custo e traduções de romances franceses no acervo do Grêmio Literário Português do Pará as mais diversas literaturas, a busca por informações acerca desses atores sociais do mundo do livro nem sempre resulta plena de sucesso. No entanto, a rápida incursão em parcela da atuação profissional dos dois tradutores anteriormente referidos parece sugerir que o universo dos livros baratos e das coleções dependia, em grande parte, desses homens, cujo perfil em termos de formação e de atuação no mercado livreiro parece longe de ser uniforme. Se, de um lado, havia quem se propusesse a traduzir e publicar romances franceses por iniciativa própria, como era o caso de João Luis Rodrigues Trigueiros, por outro lado, outros, como Francisco Ferreira da Silva Vieira, parecem ter preferido atuar ao lado de um editor em particular, oferecendo, vez ou outra, seus serviços a outrem. 0 que parece indubitável, contudo, é que a atuação desses intermediários da literatura está ainda por se investigar com mais vagar, assim como o produto resultante de sua atividade no mercado livreiro, o texto traduzido propriamente dito. Desse ponto de vista, seria necessária uma dupla perspectiva em termos de investigação: de um lado, a análise da trajetória desses profissionais, demarcando suas práticas de atuação; e, de outro, a análise dos textos por eles produzidos, uma vez que, ao que tudo indica, tal qual ocorrera com as coletâneas publicadas pelos "intelectuais" que, em fins do século XVIII, se propuseram a salvar a "cultura popular", pouco sabemos diante de que estamos: do que existia originalmente, do que o tradutor achou que existia, do que ele achou que deveria ter existido ou do que ele achou que deveria existir. ${ }^{7}$

7 A esse respeito, ver Burke (2010). 
Finalmente, cabe ressaltar que não se trata, como sugere Pascale Casanova (2002), de investigar o papel dos tradutores na consagração de autores "excêntricos" cujas obras foram vertidas para as línguas literariamente mais valorizadas da Europa Ocidental ou, ainda, o papel dos tradutores na importação de "grandes textos universais para uma língua dominada", de forma a apresentar a "modernidade decretada no meridiano de Greenwich" e, por consequência, difundir internacionalmente o capital literário "central", aumentando seu "crédito" e prestígio (CASANOVA, 2002, p. 171).

Valéria Parece-nos que parcela significativa da prosa de ficção franceAugusti sa que circulou no gabinete de leitura paraense do século XIX, assim como em outros gabinetes de leitura espalhados pelo Brasil oitocentista (SCHAPOCHNIK, 1999), gozava de pouco prestígio entre as elites letradas de seu próprio país de origem. Não por acaso, autores como Paul de Kock, a despeito do enorme sucesso de que gozava no mercado editorial francês e estrangeiro, recebiam de seus conterrâneos letrados epítetos pouco lisonjeiros, como o de "escritor das criadas graves" (PAES, 2013). Esses autores, desprestigiados pelas “autoridades literárias” dos próprios países centrais, alcançaram patamares de circulação significativos nos países que Casanova denomina "excêntricos", sendo traduzidos para as mais diversas línguas e circulando amplamente nos mais recônditos cantos não apenas da Europa, como também da América. O sucesso de vários desses autores no Brasil, atestado pela sua presença em periódicos, onde eram publicados em romance-folhetim, como também em gabinetes de leitura, como o do Grêmio Literário Português do Pará, parece-nos razão suficiente para investir no alargamento das investigações acerca desses importantes atores do mundo do livro.

\section{Referências}

ABREU, Márcia. A circulação transatlântica dos impressos: a globalização da cultura no século XIX. Livro: Revista do Núcleo de Estudos do Livro e da Edição, n. 1, p. 115-127, maio 2011.

ANDRADE, Marçal Ferreira de. História da fotorreportagem no

Brasil: a fotografia na imprensa do Rio de Janeiro de 1839 a 1900. Rio de Janeiro: Elsevier, 2004. 
AUGUSTI, Valéria. Um instantâneo presente de um acervo do passado. Colóquio Internacional "A Circulação Transatlântica dos Impressos e a globalização da cultura no século XIX (1789-1914)”. Lisboa: Universidade Nova de Lisboa, 2011. Disponível em: <http:// www.iel.unicamp.br/coloquio/files/VALERIA_AUGUSTI_por.pdf>. Acesso em: 30 abr. 2013.

BRITO, Eugênio Leitão de. História do Grêmio Literário e Recreativo Português. Belém: [s.n.], 1994.

BURKE, Peter. A descoberta do povo. In: Cultura popular na Idade Moderna 1500-1800. São Paulo: Companhia das Letras, 2010. p. 26-49.

Coleções editoriais de baixo custo e traduções de romances franceses no acervo do Grêmio Literário Português do Pará

CASANOVA, Pascale. A república mundial das letras. São Paulo: Estação Liberdade, 2002.

DARNTON, Robert. o beijo de Lamourette: mídia, cultura e revolução. São Paulo: Companhia das Letras, 1990.

EL FAR, Alessandra. Páginas de sensação: literatura popular e pornográfica no Rio de janeiro (1870-1924). São Paulo: Companhia das Letras, 2004.

GUEDES, Fernando. Os livreiros franceses em Portugal no século XVIII: tentativa de compreensão de um fenômeno migratório e mais alguma história. Lisboa: Academia Portuguesa de História, [1998].

HUGO, Victor. Os operários do mar. Lisboa: Typ. do Futuro, 1866.

LYONS, Martyn. Os novos leitores no século XIX: mulheres, crianças, operários. In: CHARTIER, Roger; CAVALLO, Guglielmo. História da leitura no mundo ocidental. São Paulo: Ática, 1999. p. 165-202.

MEIRELES, Maria Adelaide. Os livreiros no Porto no século XVII: produção e comércio. Porto: Associação Portuguesa de Livreiros Alfarrabistas, 1995. 
MOLLIER, Jean-Yves. A leitura e seu público no mundo contemporâneo: ensaios sobre História Cultural. Belo Horizonte: Autêntica, 2008.

MEMÓRIA DE LEITURA. Cronologias. Campinas, 2013. Disponível em: <http://www.unicamp.br/iel/memoria/base_temporal/Educacao/ ensino.htm>. Acesso em: 30 abr. 2013.

PAES, Alessandra Pantoja. Das imagens de si ao mundo das ediValéria ções: Paul de Kock, romancista popular. 2013. 205 f. Dissertação Augusti (Mestrado em Letras)-Universidade Federal do Pará, Belém, 2013.

36 PEREIRA, Antonio Maria. Parceria Antonio Maria Pereira: crônica de uma dinastia livreira. Lisboa: Pandora, [19--].

SCHAPOCHNIK, Nelson. Os jardins das delícias: gabinetes literários, bibliotecas e figurações da leitura na corte Imperial. 1999. 285 f. Tese (Doutorado em História)-Universidade de São Paulo, São Paulo, 1999.

SANTOS, Maria de Lourdes Lima dos. As penas de viver da pena: (aspectos do mercado nacional do livro no século XIX). Análise social, vol. XXI (86), p. 187-227, 1985-2으.

SILVA, Innocêncio Francisco da. Diccionario Bibliographico Portuguez. Lisboa: Imprensa Nacional, 1859. Tomo 3. Disponível em: <http://www.brasiliana.usp.br/bbd/handle/1918/01684303\#page/450/mode/1up>. Acesso em: 30 abr. 2013.

TRIGUEIROS, João. Familia Trigueiros: heraldica e genealogia. 2013. Disponível em: <http://familiatrigueiros.blogspot.com.br/>. Acesso em: 30 abr. 2013.

WITTMANN, Reinhard. Existe uma revolução da leitura no final do século XVIII? In: CHARTIER, Roger; CAVALLO, Guglielmo. História da leitura no mundo ocidental. São Paulo: Ática, 1999. p. 135-163. 